\title{
FRELIMO: DE UM MOVIMENTO REVOLUCIONÁRIO A PARTIDO POLÍTICO ${ }^{1}$
}

\author{
Arcénio Francisco $\mathrm{Cuco}^{2}$
}

- Enviado em 18/04/2016

- Aprovado em 20/05/2016

\begin{abstract}
RESUMO
O presente texto tem vista analisar a transformação do movimento revolucionário, FRELIMO (Frente de Libertação de Moçambique), em partido político. Partindo-se da ideia de que analisar partidos políticos não é uma tarefa fácil e que as observações mais inteligentes ainda temos que buscar dos velhos textos, como reconhece Panebianco (2005), começaremos analisando o que esses velhos textos nos oferecerem em matéria de origem dos partidos políticos, particularmente, de "Os Partidos Políticos" de Duverger (1970). Posteriormente, analisaremos o enquadramento da Frelimo, como partido político, dentro dessas teorias com o apoio de textos mais recentes como "Modelos de Partidos: Organizações e poder nos partidos políticos" de Panebianco, sem nos descurarmos das principais ideias de Sartori como autor que trabalhou de forma específica o contexto africano, naquilo que ousou designar de "O Labirinto Africano" em alusão a necessidade de o contexto africano dever ser entendido tendo em conta aspectos específicos que só dizem respeito às peculiaridades da África.
\end{abstract}

Palavras-chave: África. Frelimo. Moçambique. Movimentos Nacionalistas. Partidos Políticos.

\section{INTRODUÇÃO}

Este texto tem vista discutir, mesmo que de forma breve, a transformação da FRELIMO (Frente de Libertação de Moçambique), que desencadeou a luta armada pela independência de Moçambique de 1964 a 1974, em partido político. E porque os principais percursores das teorias dos partidos políticos como, por exemplo, Ostrogorski (1902), Michels (1911) e (Duverger (1951) pouco ou nada trataram sobre a realidade dos partidos que nasceram de movimentos revolucionários armados, as ideias de Sartori (1982) que emanam do seu livro "Partidos e Sistemas Partidários" são a principal fonte de discussão do objeto a que nos propomos debater.

\footnotetext{
${ }^{1}$ Uma versão preliminar desse trabalho foi apresentada no GT1: INSTITUIÇÕES E PODER: PARENTESCOS E GENEALOGIAS do VII Seminário Nacional de Sociologia e Política da UFPR realizado de 11 a 13 de maio de 2016 em Curitiba.

${ }^{2}$ Doutorando em Ciência Política pela UFRGS. Mestre em Ciências Criminais pela Pontifícia Universidade Católica do Rio Grande do Sul. Integrante do Grupo de Pesquisa Direito à Verdade e à Memória e Justiça de Transição e do Grupo de Pesquisa em Criminologia (GEPCRIM). Bolsista da CAPES. E-mail: arcuco@ yahoo.com.br.
} 
O livro de Sartori é importante na medida em que traz à tona uma série de questões as quais achamos que a FRELIMO passou por elas até se transformar em partido políticos, particularmente, no que tange ao fato de logo após a independência de Moçambique, a Frelimo ter se tornado o único partido político constitucionalmente aceite e como responsável por guiar os interesses da maioria dos Moçambique.

É importante sublinhar que, antes de se tornar um partido político, a FRELIMO nasce como um movimento de luta contra a ocupação de Moçambique por Portugal, potência colonizadora. De tal forma que, existe uma distinção da sigla FRELIMO como movimento revolucionário (escrita em letras maiúsculas) e da Frelimo como partido político (escrita em letras minúsculas).

Partindo-se da ideia de que analisar partidos políticos não é uma tarefa fácil e que as observações mais inteligentes ainda temos que buscar dos velhos textos, como reconhece Panebianco (2005), começaremos analisando o que esses velhos textos nos oferecerem em matéria de origem dos partidos políticos, particularmente, de "Os Partidos Políticos" de Duverger (1970). Posteriormente, analisaremos o enquadramento da Frelimo, como partido político, dentro dessas teorias com o apoio de textos mais recentes como "Modelos de Partidos: Organizações e poder nos partidos políticos" de Panebianco, sem nos descurarmos das principais ideias de Sartori como autor que trabalhou de forma específica o contexto africano, naquilo que ousou designar de "O Labirinto Africano" em alusão a necessidade de o contexto africano dever ser entendido tendo em conta o fato de que:

\footnotetext{
Os novos Estados [...] não têm tradição estatal anterior. Chamá-los de Estados é juridicamente correto, mas continua havendo uma baixa incidência de espíritos de Estado. Os novos Estados não são nem mesmo "nações", pelo menos no sentido moderno da palavra inventada pelos românticos e despertada, ou criada, pela onda napoleônica que varreu a Europa. Por outro lado, as sociedades que os novos Estados tentam governar têm uma estruturação muito mais profunda e minuciosa do que as "sociedades nacionais": são "sociedades celulares", ou sociedades mosaicos, de agrupamentos primários, atributivos, baseados no parentesco e em laços primordiais, mergulhadas na tradição, na magia e na religião. E mapeadas por imperativos territoriais. As tarefas de modernização e construção de nação cabem à política. Mas a política é precisamente a política de Estado, ainda tem de ser aprendida. Nessas condições, a única coisa definida sobre os partidos dos novos Estados em transição para alguma forma futura é uma enorme desproporção entre metas e capacidades, palavras e atos (SARTORI, 1982, p276)
}

É neste espírito que vamos tentar entender as várias transformações pelas quais a FRELIMO transitou como movimento revolucionário para partido político e único partido político constitucionalmente aceito no país logo depois da proclamação da independência. Entretanto, o nosso objetivo é analisar essa trajetória da FRELIMO buscando entender os contornos que informaram essa transformação. O principal argumento é de que a FRELIMO nasce com um 
"pseudotodo", daí a previsibilidade daquilo em que ela se transformaria logo a seguir a conquista de independência de Moçambique: único partido a traçar os destinos de todos os moçambicanos.

\section{ORIGEM DOS PARTIDOS}

Tal como o próprio Duverger (1970) aponta, os partidos são um fenômeno contemporâneo e, no sentido moderno da palavra, os partidos não existem antes de 1850 e até 1950 funcionavam na maior parte das nações (DUVERGER, 1970, 19).

O surgimento dos partidos políticos pode ser explicado a partir de várias teorias, como observam López \& Hugo (2009), nomeadamente, a teoria institucional, a qual vincula o crescimento dos partidos ao plano institucionalistas, concretamente a ideia do parlamento; teoria da crise, associada a LaPalombara e Weiner, a qual vincula o surgimento dos partidos a conflitos como guerras, explosões demográficas, depressões econômicas e; a teoria da modernização segundo a qual os sistemas políticos passam por muitas reformas institucionais e crises históricas, mas a formação dos partidos não foi sempre sua derivação. Os partidos poderiam ser mais bem vestígios de um certo processo de modernização, em virtude de uma decisão de os cidadãos influírem no poder, de uma parte de a elite governante querer apoio popular, pelas mudanças econômicas, por aí em diante.

Entretanto, para Duverger (1970), a origem de um partido político influência o seu desenvolvimento e, esse desenvolvimento, parece, também, associado ao desenvolvimento da democracia, ou seja, à extensão da participação das pessoas na vida pública e na sociedade política através do sufrágio popular e das prerrogativas parlamentares (DUVERGER, 1970, 19, 20). E, essa origem, vai influenciar também a gênese dum partido sobre a sua estrutura definitiva. Para este autor, a gênese do partido situa-se fora do ciclo eleitoral e parlamentar, formando essa exterioridade, aliás seu caráter comum mais nítido.

A constatação de Charlot (1971) é de que, os partidos surgem em um quadro político já diferenciado, em uma cultura política nacional geralmente bem solidificada, o que não ocorre na maior parte dos novos Estados do Terceiro Mundo, onde os partidos aparecem ao mesmo tempo que o Estado, numa espécie de um vazio institucional. Sendo assim, o modelo institucionalista de Duverger parece aplicar-se especialmente ao caso particular dos países europeus ou norteamericanos que fizeram sua unidade nacional - o que ainda exclui a Alemanha e a Itália - e experimentaram um sistema de representação política antes do aparecimento dos partidos políticos modernos. Daí o número de países do terceiro mundo com sistema unipartidário, pois: 
“(...) Os movimentos nacionalistas, uma vez no poder, dispõem de certa maneira de uma tábula rasa sobre a qual construir podem, se desejarem, suprir o próprio sistema parlamentar. Em suma, só têm que contar com eles mesmos. Não têm herança política" (CHARLOT 1971, p.9).

Trata-se de uma ideia que vai ao encontro da posição do Sartori citada anteriormente que enfatiza a ausência de uma tradição estatal anterior, aos Estados que surgiram como resultado de uma luta armada de movimentos nacionalistas, assunto que abordaremos mais adiante.

\subsection{PARTIDOS POLÍTICOS}

Para estabelecer o conceito de partidos políticos, Panebianco (2005) parte de dois preconceitos predominantes na literatura sobre os partidos, designadamente: preconceito sociológico e preconceito teleológico. O preconceito sociológico consiste em considerar as atividades dos partidos como o resultado das demandas dos grupos sociais por eles representados e, mais em geral, que os próprios partidos nada mais são do que a manifestação das divisões sociais em âmbito político. Na perspectiva do preconceito sociológico, expressões como "partidos operários", "partidos burgueses", "partidos camponeses" são utilizados apenas para fins sociográficos, para descrever a composição social predominante dos eleitores e/ou dos filiados aos diferentes partidos, mas disso também se infere a explicação do comportamento dos próprios partidos.

Mas, esta visão dos partidos políticos, segundo o autor demanda consequências. Uma das mais comum é a tendência em se interpretar os conflitos internos dos partidos exclusivamente como conflitos entre representantes de interesses sociais diferentes. A outra consequência é atribuir a eventuais desvios entre a composição do eleitorado e a composição dos filiados, dos militantes e dos representantes eleitos do partido a causa de distorções na representação dos interesses sociais. $\mathrm{O}$ preconceito sociológico não deixa ver que, entre os partidos e o sistema das desigualdades sociais, existe uma relação complexa, o que vai impedir que se represente corretamente as complexas relações entre o partido e o seu eleitorado quanto que sejam individuadas as desigualdades específicas inerente ao agir organizativo como tal.

Já o preconceito teleológico consiste em atribuir, a prior, alguns "objetivos" aos partidos, que, segundo o observador, representam a razão de ser do partido em exame, dos partidos em geral ou de uma ou outra "família ideológica". O que origina esse modo de proceder é a ideia de que os 
partidos são organizações constituídas em vista de objetivos específicos e voltadas à sua realização, objetivos que o pesquisador considera facilmente individualizáveis de uma vez por todas.

Entretanto, LaPalombara \& Weiner (1966) definem os partidos políticos a partir de quatros pressupostos, a saber: (i) Uma organização durável, ou seja, uma organização cuja esperança de vida política é superior à de seus dirigentes no poder; (ii) uma organização local bem estabelecida e aparentemente durável, mantendo relações regulares e variadas com o escalão nacional; (iii) a vontade deliberada dos dirigentes nacionais e locais da organização de chegar ao poder e exercê-lo, sozinhos ou com outros, e não simplesmente influenciar o poder e; (iv) a preocupação, enfim, de procurar suporte popular através de eleições ou de qualquer outra maneira.

Ao trazermos estes conceitos de partidos políticos, queremos mostrar como o debate em entorno do mesmo estão sendo levados a cabo. Não se trata, no entanto, de apoiar este ou aquele conceito dos autores apresentado, pois nos interessa mais encontrar alguma interseção entre estes conceito e a Frelimo como partido político.

Entretanto, também, fica implícito que as ideias ancestrais dos partidos políticos, tais como clubes, comités notáveis, clubes, ligas são excluídos da percepção do que sejam os partidos políticos, que é visão na qual o texto se centra ao se apresentar os conceitos anteriores. Ou seja, olharmos o partido como um todo ou, ainda como simplesmente a existência de um pluralismo partidário, e não unipartidarismo, que foi a principal característica dos Estados africanos criados pelos movimentos nacionais logo após as independências dos seus países. Sendo assim, parece importante apresentar o que nos propomos defender ao tratarmos sobre o pluralismo partidário.

\subsubsection{Pluralismo Partidário/o Labirinto Africano}

Para entendermos a transformação da FRELIMO como partido político parece importante perpassarmos de forma breve pela ideia de pluralismo partidário, pois parece que o conceito principal na qual se assenta o conceito ocidental do partido teve uma interpretação diversa em África. Não obstante alguns novos Estados africanos terem adotado o pluralismo partidário (que ao mesmo tempo pode significar democracias, segundo Sartori), posteriormente houve uma tendência do desaparecimento de partidos e instalando-se, na maioria deles, o unipartidarismo. Isso pode pressupor, numa primeira constatação que, possivelmente, as condições necessárias para a eclosão, sobrevivências e/ou convivência pluripartidária não estavam preenchidas ou porque os grupos autodesignados partidos não eram partidos no sentido em que entendemos os partidos modernos, ou mesmo, no sentido próprio do termo. 
A expressão "pluralismo" pode ser conceituada em três níveis: (i) cultural, (ii) societal e (iii) político. No primeiro nível fala-se de uma cultura pluralista no mesmo sentido que as noções paralelas da cultura secularizada e de cultura homogênea. Para Sartori (1982), uma cultura pluralista traz uma visão do mundo assente na essência, "na convicção de que a diferença, e não a semelhança, a dissensão e não a unanimidade, a mudança e não a imutabilidade, levam a uma vida melhor" (SARTORI, 1982; p.35). O autor considera este pluralismo como filosófico ou a teoria filosófica do pluralismo, em sua diferença da realidade do pluralismo.

O autor afirma que, com relação ao segundo nível, o pluralismo societal deve ser distinguido da diferenciação societal porque ambos são estruturas societais ou, mais exatamente, princípios estruturais que resumem configurações sócio-estruturais. Mas, o fato de que toda a sociedade complexa se revela "diferenciada", não se segue de modo algum que todas as sociedades sejam diferenciadas "pluralisticamente". Uma sociedade plural não é uma sociedade pluralista, pois esta última é apenas um dos muitos tipos possíveis de diferenciação societal. Com relação ao terceiro nível, o autor afirma que o pluralismo político indica uma "diversificação do poder" e, mais precisamente, a existência de uma "pluralidade de grupos que são ao mesmo tempo independentes e não-inclusivos.

Ao apresentarmos este conceito, a ideia é de tentar mostrar que o pluralismo não consiste simplesmente de associações múltiplas. Estas devem ser, como Sartori defende, em primeiro lugar, voluntárias (e não atributivas) e, em segundo lugar, não exclusivas, isto é, baseadas em afiliações múltiplas - sendo estas o traço marcante crucial de uma estruturação pluralista. A presença de um grande número de grupos identificáveis não comprova, de algum modo, a existência do pluralismo, mas apenas um estado desenvolvido de articulação e/ou fragmentação:

As sociedades multigrupais são "pluralistas se, e apenas se, os grupos forem associativos (e não consuetudinários ou institucionais) e, o que é mais, só quando se puder constatar que as associações se desenvolveram naturalmente, que não são "impostas". Isso exclui notadamente o chamado pluralismo africano, que na realidade gira sobre grupos comunais consuetudinários e resulta em uma cristalização fragmentada. Exclui igualmente o sistema de estratificação por castas (SARTORI, 1982, p.38)

Neste ínterim, queríamos chegar ao pluralismo partidário. A expressão tem na realidade mais profundidade de significados do que se atribuí geralmente (SARTORI, 1982). Tomado por seu valor aparente, o pluralismo partidário indica simplesmente a existência de mais de um partido; mas a conotação é a de que os partidos no plural são o produto do pluralismo. Mas o fato de que a legitimação e o funcionamento normal do pluralismo partidário se baseiam na aceitação do 
pluralismo simplesmente, sem adjetivos, continua sendo um fator secundário. Não contribui para explicar, entre outras coisas, por que sistemas partidários se desenvolveram de uma determinada maneira, nem o papel que o sistema partidário chegou a desempenhar dentro do sistema político geral. Isso pode ser entendido a partir da ideia da ausência de partidos e/ou partido único.

Os Estados de partido único só surgiram depois da Primeira Guerra Mundial, e, até então, a expressão "sistema unipartidário" parecia ser uma contradição nos termos. Para Sartori (1982), de acordo com a rationale do pluralismo partidário, se um partido não for uma parte, é um pseudopartido; e se o todo se identificar com apenas um partido é um pseudotodo. Nesse sentido entramos na natureza suis generi do partido único, que foi a principal característica dos novos Estados africanos.

O partido único é um partido da elite com limitado número de membros, um partido de vanguarda que serve de percursor do todo. Mesmo assim, o partido único não é uma "parte" em nenhum dos sentidos nos quais o são os partidos no plural. $\mathrm{O}$ partido único evidencia as características do holismo, ou de totalidade, ao rejeitar integralmente a ideia de um todo resultante de uma influência mútua competitiva entre as partes. Mesmo, dentro do partido único, qualquer tipo de divisão intrapartidária formalizada é proibido: "é uma heresia, um desvio intolerável" (SARTORI, 1982, p.60)

Para Sartori, embora "um todo" seja sempre maior do que uma parte, sempre que é representado apenas por um partido deixará de ser um todo imparcial, um todo acima de suas partes:

Enquanto um todo pluralista é multilateral, um todo monista é unilateral. Não só uma parte sem contrapartida é uma pseudoparte, como também um todo que não encerre partes (no plural) carece da totalidade de um todo real - é um todo "parcial" em ambos os sentidos: exclui e toma partido (SARTORI, p.63)

A importância de trazer estas ideias tem a ver com o fato de em 1960, Almond ter classificado os sistemas partidários de acordo com cinco tipos: (1) totalitário, (2) autoritário; (3) não-autoritário dominante; (4) competitivo bipartidário e (5) multipartidário competitivo. Trata-se de uma classificação que tem como novidade no terceiro tipo: a categoria de não-autoritário dominante, com qual Almond designou os sistemas políticos onde os movimentos nacionalistas foram importantes para a obtenção da emancipação. É um tipo de categoria que Sartori considera $a d$ hoc uma vez que ela só serve de ponte entre o "unipartidarismo e o bipartidarismo" (SARTORI, 1982, p.274-275). A questão que ressalta é: por conta desta categoria de Almond, poderíamos ilibar os movimentos nacionalistas pela implantação de unipartidarismo durante o nascimento dos Estados 
africanos, modelo também seguido pela FRELIMO no momento que se seguiu a independência do país? E o fator ideológico?

Sartori dá-nos respostas interessantes. A primeira é que, embora haja muito poucas evidências de que fatores ideológicos realmente tenham tido relevância empírica em contextos africanos, o que está claro é que a maioria do que é considerado como ideologia é apenas retórica política e, ao mesmo tempo, venda de imagem aos públicos ocidentais. A outra é a que citamos anteriormente, segundo a qual os novos Estados não tinham uma tradição estatal anterior, qualquer forma de governo para eles poderia ser implantada, independentemente das consequências. Resultado, a maioria dos países que se tornaram independentes até 1974, chamaram atenção pela rápida ascensão de governos unipartidários (conforme o quadro abaixo) e na maioria desses países os governos civis em média duraram cinco anos - e nenhum lugar chegaram a 10 anos - em todos os países subsaarianos atingidos por golpes (pela primeira vez) entre 1960 e 1970.

Quadro 1. Golpes na África (da independência até 1975)

\begin{tabular}{|c|c|c|c|c|}
\hline & & \multicolumn{3}{|c|}{ Antes do Golpe } \\
\hline País & $\begin{array}{c}\text { Ano de } \\
\text { independência }\end{array}$ & Dominante/Unipartidário & Multipartidário & Golpe(s) militares \\
\hline Congo (Kinshasa) & 1960 & & $\mathrm{X}$ & $1960 / 1965$ \\
\hline $\begin{array}{l}\text { Congo } \\
\text { (Brazzaville) }\end{array}$ & 1960 & & $\mathrm{X}$ & $1963 / 1968$ \\
\hline Daomé (Benin) & 1960 & $\mathrm{X}$ & & $1963 / 65 / 67 / 69 / 72$ \\
\hline Togo & 1960 & & $\mathrm{X}$ & $1963 / 1967$ \\
\hline Burundi & 1962 & $\mathrm{X}$ & & $1966 / 1966$ \\
\hline $\begin{array}{l}\text { República Centro- } \\
\text { Africana }\end{array}$ & 1960 & $\mathrm{X}$ & & 1966 \\
\hline $\begin{array}{l}\text { Alto Volta (Burkina } \\
\text { Faso) }\end{array}$ & 1960 & $\mathrm{X}$ & & 1966 \\
\hline Nigéria & 1960 & & $\mathrm{X}$ & $1966 / 1966 / 1975$ \\
\hline Gana & 1957 & $\mathrm{X}$ & & $1966 / 1972$ \\
\hline Uganda & 1962 & $\mathrm{X}$ & & $1966 / 1971$ \\
\hline Serra Leoa & 1961 & & $\mathrm{X}$ & $1967 / 1968$ \\
\hline Mali & 1960 & $\mathrm{X}$ & & 1968 \\
\hline Somália & 1960 & & $\mathrm{X}$ & 1969 \\
\hline Lesoto & 1966 & $\mathrm{X}$ & & 1970 \\
\hline Ruanda & 1962 & $\mathrm{X}$ & & 1973 \\
\hline Níger & 1960 & $X$ & & 1974 \\
\hline Chade & 1960 & $\mathrm{X}$ & & 1975 \\
\hline Sudão & 1956 & & $\mathrm{X}$ & $1958 / 1964 / 1969$ \\
\hline Argélia & 1952 & $X$ & & 1965 \\
\hline Líbia & 1962 & - & - & 1969 \\
\hline Etiópia & - & - & - & 1974 \\
\hline Moçambique $^{3}$ & 1975 & $X$ & & \\
\hline
\end{tabular}

Fonte: Sartori, 1982, p.279

\footnotetext{
${ }^{3}$ Acréscimo do autor.
} 


\subsection{FRELIMO: UM “PSEUDOTODO” À NASCENÇA}

Os dados anteriores podem nos permitir perceber a trajetória da FRELIMO de um movimento revolucionário à partido político se se considerar que ela também passou por todos os dilemas experimentados por quase maior parte dos movimentos revolucionários da África subsaarianos. Tratado como movimento terrorista pelos colonizadores (NEVES, 1965), foi reconhecido internacionalmente como o único movimento que lutava pela independência de Moçambique, recebendo solidariedade de vários países do mundo em, particular do bloco soviético. Provavelmente tenhamos aqui o principal sinal daquilo que iria definir a linha da FRELIMO para a governação de Moçambique após a independência: o unipartidarismo.

A FRELIMO, como movimento de libertação de Moçambique da colonização portuguesa, é criada em 1962 como resultado de junção de três movimento de luta contra a ocupação colonial portuguesa, nomeadamente, UDENAMO (União Democrática Nacional de Moçambique), MANU (Mozambique African National Union) e UNAMI (União Africana de Moçambique Independente). Transformou-se em partido político após a realização do seu $3^{\circ}$ Congresso em 1977 (dois anos depois da proclamação da independência do país) como um partido marxista-leninista de orientação socialista (NUVUNGA, 2007, MANNING, 2007).

Estava claro desde a declaração da independência do país, em 1975, que a Frelimo não iria optar pelo pluralismo partidário, ou seja, iria optar por pseudotodo sartoriano, que consiste na ausência de "diversificação do poder". Todo o poder ir-se-ia concentrar num único partido. O artigo $3^{\circ}$, da primeira Constituição da República (1975) é elucidativo em relação a este aspecto ao preconizar a República Popular de Moçambique como orientada pela Frelimo, como força dirigente do Estado e da sociedade: “(...) A FRELIMO traça a orientação política básica do Estado e dirige e supervisa a ação dos órgãos estatais a fim de assegurar a conformidade da política do Estado com os interesses do povo" (CRM, artigo 3º, Boletim da República, quarta-feira, 25 de junho de 1975).

As perguntas que ressaltam são as seguintes: é condenável, a Frelimo, por ter optado por esta via? Será que existiam condições favoráveis a uma via pluripartidária? Como referimos anteriormente, Sartori defende a ideia de que possivelmente condições necessárias para a eclosão, sobrevivências e/ou convivência pluripartidária não estavam preenchidas: seria esta proposição aplicável para o caso da Frelimo?

Olhando-se para o quadro 1, pode-se perceber que até 1975, ano em que Moçambique alcança a independência, poucos países tinham optado, durante o nascimento das suas repúblicas, pelo pluripartidarismo. Outro elemento que parece fundamental, é que os principais países que 
apoiaram a FRELIMO durante a luta de libertação nacional (nomeadamente, URSS, China, Cuba, Argélia entre outros), também eram regimes unipartidários. Os primeiros contatos com os ideais socialistas, segundo Cabaço (2010), ocorreram ainda durante a luta contra o colonialismo e, por diferentes vias, sendo uma das mais importantes a leitura de textos sobre a guerra revolucionária, “em particular os livros de Mao Tse Tung e do general vietnamita Nguyen Giap” (CABAÇO, 2010, P.291). Para além disso, o apoio logístico para a guerra e o treinamento militar eram concedidos, exclusivamente, pelos países socialistas (URSS, China e alguns países africanos da mesma linha que a altura já eram independentes, casos da Argélia, Zâmbia e Tanzânia), fato que aproximou o movimento de libertação à esfera política socialista. Para agravar esta situação, o país colonizador de Moçambique (Portugal) também não era referência neste aspecto.

Por todas estas razões parece que, de algum modo, o "pseudotodo" frelimista é justificável considerando o fato de que não tinha tido uma experiência democrática anterior, uma vez que a potência colonizadora (Portugal) passava, também, por um regime ditatorial até às vésperas da independência de Moçambique. Ou seja, diferentemente dos países como Zimbabué, Namíbia, Nigéria, Gana, Senegal, Sudão que tiveram uma experiência democrática das suas potências colonizadoras (Inglaterra e França), e, por conseguinte, logo depois das suas independências introduziram o pluralismo partidário (embora alguns desses países tenham sofrido processos reversivos ao longo do tempo devido aos golpes de estado, como ilustra o quadro 1), a experiência de Moçambique resulta de um país colonizador que viveu uma ditadura até um curto espaço de tempo anterior às independências das colônias portuguesas. A ditadura do Salazar combatia os partidos políticos quer em Portugal quer nas suas respectivas colônias e, aqueles partidos políticos que atuavam na clandestinidade sofriam uma grande infiltração das forças de segurança portuguesa (MAXWELL, 1988).

Infelizmente, esta experiência também foi adotada pela Frelimo durante o período da vigência do regime partido/Estado, combatendo todo o tipo de oposição à revolução frelimista, o que hipotecou a possibilidade de introdução do pluripartidarismo em Moçambique. Aliás como Ngoenha (2014) sublinha, os movimentos de luta contra a dominação colonial acabaram presos a questões do poder:

Os revolucionários ficaram presos às ideologias que os guiavam, quando ainda não tinham nenhum poder, quando não eram reconhecidos e eram obrigados a uma clandestinidade continuamente ameaçada por perseguições terríveis. O poder era externo e devia ser abatido. O poder estava armado e corriam armas para derrubá-lo. Por isso, parecia lícito ter uma organização interna de ferro, onde o "centralismo democrático" comportava a delegação absoluta nos chefes, exatamente como nos exércitos, pela sua natureza autocrática. Mas os revolucionários conseguiram tomar 
o poder. Todavia, a organização militar ficou intacta, não obstante a tomada parcial ou completa do poder. (NGOENHA, 2014, 169).

Ou seja, a despeito de procuraram criar novas estrutura, mantiveram as estruturas organizativas militares criadas durante a luta armada, ao mesmo tempo que mantinham as estruturas administrativas herdadas do colonizador, que ao invés de servir aos interesses nacionais, acabaram por servirem à ideologias que deram vazão a revoltas populares e, na maior parte dos casos, no surgimento de rebeliões. Para o caso de Moçambique, o tempo inclusive se encarregou de contrariar as pretensões da FRELIMO, que através da constituição de 1975 (que proclamou a República Popular) preconizava como um dos objetivos, nos seu artigo $4^{\circ}$ "a eliminação das estruturas de opressão e exploração coloniais...", assim como a criação de uma lei eleitoral que fixarias as condições, modo e data das eleições gerais, cujas primeiras ocorreriam depois da realização do III Congresso da FRELIMO realizada em 1977 (artigo 39º), que transformou o movimento em partido político e único representante dos interesses do Estado com todas as características apresentadas por Sartori (1982): holismo, rejeitando integralmente a ideia de um todo resultante de uma influência mútua competitiva entre "partes" (entendido como partidos na visão sartoriana).

Talvez o maior pecado da Frelimo, nesta questão, tenha sido o fato de se ter afastado da cultura pluralista, ao querer homogeneizar uma sociedade culturalmente heterogênea, com a política de "criação do homem novo", quando, como Sartori tentou ilustrar, a diferença e não a semelhança a dissensão e não a unanimidade, a mudança e não a imutabilidade são os pilares que levam a uma vida melhor. A "criação do homem novo" impunha a reprovação de certos rituais e crenças tradicionais, a obrigatoriedade do uso da língua portuguesa nas escolas e em lugares públicos. Nesse sentido vários adjetivos depreciativos dos rituais e crenças tradicionais foram criados e bastante repetidos em reuniões e encontros populares. Com esta atitude, a Frelimo esperava que a extinção dessas crenças arrastasse consigo a desagregação de mitos, símbolos e valores, desconstruindo velhas estruturas protetoras, para se recomporem na estrutura protetora do "pseudotodo". E se não era possível uma unidade construída na base das diferenças e não nas semelhanças, ficava claro que, também não seria possível a existência de uma pluralidade de grupos que poderia consubstanciar o pluralismo político.

\footnotetext{
${ }^{4} \mathrm{Na}$ óptica da FRELIMO, o "homem novo" representava uma oposição ao homem velho que se configura como uma contaminação da sociedade colonialista, razão pela qual, o mesmo devia dar corpo a uma identidade moçambicana. E, isso, implicava a necessidade de criação de novas relações sociais que implicavam profundas mudanças, tais como a estatização dos meios de produção, a centralização das decisões no aparelho do Estado, a homogeneização das individualidades, o que exigia um Estado forte, apoiado no partido, no exército e uma máquina burocrática, também muito forte (COLAÇO, 2001, P.97)
} 


\subsubsection{Adaptação ao Pluripartidarismo}

Vários dos problemas decorrentes do unipartidarismo refletiram-se quando se decidiu pela introdução do pluripartidarismo, em 1992, com o fim da guerra civil que tinha deflagrava o país desde 1976, que opunha o governo da Frelimo e a Renamo (Resistência Nacional de Moçambique). Aliás essa situação não foi só pela parte da Frelimo, inclusive a outra parte signatária do Acordo Geral de Paz que deu espaço para o pluripartidarismo, a Renamo também se ressentiu dessa situação, pois tanto a Frelimo como a Renamo confrontaram-se com os mesmos problemas de adaptação ao pluripartidarismo, embora de maneira peculiar, tendo em conta as especificidades históricas de cada uma das organizações. Quer o líder da Frelimo, Joaquim Chissano, quer o líder da Renamo Afonso Dlhakama enfrentaram o desafio múltiplo de garantir a sobrevivência organizacional, proteger suas próprias posições à frente do partido, e buscar apoio eleitoral para o partido (MANNING, 2007). Situação naturalmente compreensível, considerando que em períodos de transições, em relação a determinados temas, como sublinham O’donnell \& Schmitter (1986), é quase impossível especificar, ex ante, classes, setores, instituições e outros grupos que vão assumir este ou aquele papel, ou ainda, optar por este ou aquele elemento ou apoiar uma ou outra alternativa. O corolário desta situação é o que se pode depreender do trecho que se segue:

\footnotetext{
Na verdade, é possível que a única coisa que possamos dizer seja que, no decorrer do momentos e escolhas cruciais de um período de transição, a maioria - senão a totalidade - dos atores provavelmente estará dividida ou hesitante com relação aos e ideais e, por tanto, incapaz de promover qualquer ação coerente. Além disso, aqueles atores provavelmente passarão por mudanças significativas conforme tentem dar resposta aos contextos em transformação que lhes são apresentados pela democratização e liberalização (O’DONNELL \& SCHMITTER, 1986, p.19).
}

Ou seja, os atores principais de uma transição política têm de enfrentar vários dilemas e incertezas uma vez que o processo ocorre num momento de quase ausência de instituições pluralistas; em que as regras do jogo político não estão definidas e as que existem estão sujeitas a mudanças constantes e contestação. Tal como O’donnell \& Schmitter (1986) sustentam, trata-se de uma fase em que os atores principais lutam não só para satisfazer interesses imediatos e/ou os interesses daqueles a quem se propõem a representar, como também pela definição de regras e procedimentos cuja configuração determinará prováveis vencedores e perdedores no futuro.

Esta situação foi sentida no país e acabou jogando um papel importante e, também funcionou como o principal aspecto que ressaltou as diferenças entre as duas partes no que tange à institucionalização dos dois partidos políticos para o enfrentamento dos desafios das primeiras eleições presidenciais e pluripartidárias de 1994, que marcaram o auge do processo de 
democratização de Moçambique. Em 1994, a Frelimo estava mais avançada em termos de desenvolvimento da sua estrutura institucional. Ou seja, os quinze anos de experiência anterior de governação unipartidária acabaram sendo determinantes para a Frelimo, uma vez que já possuía uma estrutura institucional de decisão partidária em todos os níveis (local, bairro, cidade, distrital e provincial), o que permitia a seleção de candidatos para diferentes hierarquias (partidária ou estatal) sem muitas dificuldades.

Para Manning (2007), a transição política colocou exigências novas e tremendas ao partido Frelimo como uma organização. Essas exigências foram atendidas em parte pelo desenvolvimento de novas estruturas internas, bem como o reforço dos já existentes (para a gestão de conflitos intraorganizacional, a seleção de liderança e de gestores para questões do partido e da política nacional) que haviam servido muito bem ao partido durante a transição para o pluripartidarismo.

Por seu torno, a Renamo não disponha de estrutura partidária estabelecida no início da transição democrática. Contrariamente à Frelimo, a Renamo foi obrigada a lidar com os desafios organizacionais apresentadas pela transição para a vida política e civil por políticas democráticas competitivas de uma só vez. O défice organizacional foi notório. Embora o partido tivesse as estruturas necessárias e regulamentos no papel, eles nunca realmente funcionaram. Terá contribuído, para esse fato, como aponta Manning (2007), a natureza extremamente centralizada e personalizada da Renamo, que pouco mudou desde o fim da guerra. Mesmo quando o partido realiza reuniões, poucas são as evidências de que algo impactante possa surgir em termos de reforços ao debate interno entre os membros sobre questões estratégicas de fundo que possam servir como base de sustentação do próprio partido: "Do ponto de vista de Dhlakama, qualquer tentativa de estabelecer uma estrutura de tomada de decisões com autoridade única poria em causa seu controle sobre o partido" (MANNING, 2007, p. 202).

Em algum momento o seu discurso entra em dissintonia com a posição dos seus membros, como, por exemplo, aconteceu em 2010, quando 22 dos 51 deputados eleitos do seu partido tomaram posse na Assembleia da Republica à revelia do seu líder, após lhes proibir esse ato; ou ainda a expulsão do Raul Domingos, em julho de 2000 (seu possível sucessor e segundo homem "forte" e negociador-chefe em Roma do partido), sem sequer consulta dos principais órgãos do partido (BERGH, 2009, MANNING, 2007). Ou seja, o partido é o líder. O resto dos órgãos são "honoríficos". Talvez esta postura justifique o recurso ao discurso belicista do líder da Renamo (embora, hodiernamente, está postura não seja apenas da Renamo) para fazer vingar suas posições. Trata-se de um agir que reforça a ideia de existência de um défice organizacional dentro da Renamo. Entretanto, o discurso em si tem funcionado já que, geralmente, têm conseguido empurrar 
as lideranças da Frelimo para aquilo que Manning (2007), chama de "negociações de bastidores", que muitas vezes desrespeitam às instituições democráticas (negociações fora das instituições democráticas, ao exemplo da Assembleia da República) e excluem outros atores do processo de democratização do país, como por exemplo, a sociedade em geral. Este elemento, também mostra a tendência de polarização do processo de democratização de Moçambique entre a Frelimo e a Renamo.

Em suma, não existe, ainda, um pluralismo partidário puro em Moçambique devido a esta polarização Frelimo/Renamo, que inúmeras vezes atuam sem respeito aos princípios pluripartidário, ou seja, como se fossem únicos representantes legítimos dos interesses dos moçambicanos.

\section{CONSIDERAÇÕES FINAIS}

Podemos dizer que, não é possível falar da transformação da FRELIMO em partido político sem olharmos para os dilemas pelos quais maior parte do novos Estados africanos no período que se seguiu as suas independências territoriais passaram. Igualmente, parece difícil olhar para a transformação da FRELIMO como um partido político de igual maneira como são vistos os partidos políticos em países com pluralismo político já consolidado.

Parece que a ponderação que Sartori tem, em relação aos labirintos africanos, seja bastante importante para podermos começar a traçar uma visão distinta dos partidos políticos africanos, considerando-se todas características peculiares, nomeadamente, a tradição estatal, a ideia da pluralidade societal, pluralidade cultura que de alguma forma acabam influenciando negativo ou positivamente para a pluralidade partidária. Isso permitiria que nos afastássemos de considerar apenas traços característico de partidos políticos de sociedade cujo pluralismo político se encontra enraizado. Partindo-se deste pressuposto possivelmente podemos perceber facilmente o que levou a maior parte dos movimentos revolucionários africanos, a exemplo da FRELIMO, a optarem pelo unipartidarismos e não outra forma de regime. Ou ainda, percebermos por que determinados movimentos nacionalistas que começaram privilegiando o pluralismo partidário, a dado momento recuaram para o unipartidarismo. Desta forma, queremos dizer que, a transformação dos movimentos revolucionários dos novos Estados africanos merece uma análise específica despida do olhar a partir de pluralismos partidários consolidadas, mas sim como realidade peculiar a outras realidades, que se afastam das ideias de teóricos como Duverger, Panebianco, dentre outros. 
Entretanto, importa sublinhar que, em termo de características, olhando-se a definição de LaPalomba \& Weiner, desde que, em 1977, a Frelimo se transformou em partido político, observase que mantém todas características que estes autores apresenta: uma organização durável; bem estabelecida e mantém relações regulares e variadas com o escalão nacional (através de congressos e assembleias e reuniões do Comité Central); a vontade deliberada dos dirigentes nacionais e locais da organização de chegar ao poder e exercê-lo, sozinhos ou com outros, e não simplesmente influenciar o poder; a preocupação, enfim, de procurar suporte popular através de eleições ou de qualquer outra maneira.

\section{REFERÊNCIAS}

CABAÇO, José Luís. Moçambique: Identidades, Colonialismo e Libertação; Editora Marimbique Conteúdos e Publicações, Lda, Maputo, 2010.

CHARLOT, Jean. Os partidos Políticos. Série Pensamento Político. Editora Universidade de Brasília. Brasília, 1971.

COLAÇO, João Carlos. Trabalho como política em Moçambique: do período colonial ao regime socialista. In: Moçambique ensaio; FRY, Peter (organizador), Editora UFRJ, 2001, p97.

Constituição da República Popular de Moçambique: Boletim da República, quarta-feira, 25 de junho de 1975

DUVERGER, Maurice. Os partidos Políticos. Editora Guanabara, $3^{\mathrm{a}}$ Edição. Zahar Editores. Rio de Janeiro, 1970.

LAPALOMBARA, Joseph, WEINER, Myro. The origin and development of political parties. CHARLOT, Jean. Os partidos Políticos. Série Pensamento Político. Editora Universidade de Brasília. Brasília, 1971.

LÓPEZ, Martínez, HUGO, Víctor. Partidos políticos: un ejercicio de clasificación teórica. Perfiles Latinoamericanos, núm. 33, enero-junio, 2009, pp. 39-63

MANNING, Carrie. Revolutionaries to Politicians: The Case of Mozambique. In: DEONANDAN, Kalowatie; CLOSE, David; PREVOST, Gary. From Revolutionary Movements to Political Parties: Cases from Latin-American and Africa.PALGRAVE MACMILLANTM, 2007. P.181-210.

MAXWELL, Kenneth. A Derrubada do Regime e as Perspectivas de Transição Democrática em Portugal. In: O’DONNELL, Guillermo; SCHIMITTER, Philippe C. WHITEHEAD, Laurence. Transições do Regime Autoritário Sul da Europa. Editora Vértice, São Paulo, 1988. 
NEVES, João Alves das, Raízes de Terrorismo em Angola e Moçambique (1969), Gráfica Imperial, Lisboa, 1970.

NGOENHA, Severino. Intercultura, alternativa à governação biopolítica? PubliFLX. Maputo. Dezembro de 2013.

NUVUNGA, Adriano. Experiências com Partidos Políticos em Novas Democracias. O 'deixa andar no quadro institucional em Moçambique. IN: Cadernos ADENAUER VIII (2007), $\mathrm{n}^{\circ} 3$ : Partidos políticos: quatro continentes. p. 53-74.

O’DONNELL, Guillermo; SCHMITTER, Phillipe. Transições do regime Autoritário: Primeiras Conclusões. Edições Vértice, São Paulo, 1986.

SARTORI, Giovani. Partidos e Sistemas Partidários. Série Pensamento Político. Editora Universidade de Brasília. Brasília, 1982.

\title{
FRELIMO: FROM A REVOLUTIONARY MOVEMENT TO POLITICAL PARTY
}

\begin{abstract}
This paper seeks to analyze the revolutionary movement, FRELIMO (Mozambique Liberation Front) transformation into a political party. Starting from the idea that political parties analyze is not an easy task and that the most intelligent observations still have to get in the old texts as Panebianco (2005) as recognized, we will start analyzing what these old literature offer us in terms of origin of political parties, in particularly the "political parties" of Duverger (1970). Then, we will examine the framework of Frelimo, as a political party within these theories supported of more recent texts as "Parties models: Organizations and power in political parties" of Panebianco. Therefore, we are not neglecting the major Sartori ideas as an author who worked specifically the African context, what we dared to designate "the African Labyrinth" in reference to the need for the African context should be understood taking into account specific aspects that relate only to the peculiarities of Africa.
\end{abstract}

Key-words: Africa. Frelimo. Mozambique. Nationalist movements. Political parties. 